\title{
TURISMO Y DESARROLLO VITIVINÍCOLA EN ESPACIOS DE MONTAÑA CON "ALTA DENSIDAD PATRIMONIAL"1
}

\author{
Eugenio Baraja Rodríguez* \\ Universidad de Valladolid \\ Daniel Herrero Luque** \\ Universidad de Burgos \\ Marta Martínez Arnáiz**** \\ Universidad de Burgos \\ Juan Ignacio Plaza Gutiérrez**** \\ Universidad de Salamanca
}

\section{RESUMEN}

El fomento del enoturismo se está convirtiendo en una estrategia cada vez más frecuente en las comarcas vitivinícolas del Duero que han consolidado su faceta productiva en torno a los vinos de calidad, y que ahora ponen en valor los elementos patrimoniales de unos paisajes vinculados al productivismo. Pero al tiempo, en los entornos más frágiles, en los espacios menos transformados y de alta concentración de bienes patrimoniales que los han posicionado como destinos turísticos, este sector está operando como palanca de reactivación y de inserción competitiva de unos viñedos cada vez más reconocidos y valorados. Para ilustrar este proceso, el artículo analiza la dinámica de unos viñedos cultivados en entornos de "alta densidad patrimonial", la Sierra de Salamanca.

Palabras clave: Turismo, patrimonio, vino, paisaje, Sierra de Salamanca (España).

Fecha de recepción: 23 de mayo de 2018

Fecha de aceptación: 12 de noviembre de 2018

*Departamento de Geografía. Facultad de Filosofía y Letras. Universidad de Valladolid. Plaza del Campus, s/n. 47011 VALLADOLID (España).E-mail: baraja@fyl.uva.es

**Departamento de Historia, Geografía y Comunicación. Facultad de Humanidades y Comunicación. Universidad de Burgos. Paseo de los Comendadores, s/n. 09001 BURGOS (España).E-mail: dhluque@ubu.es

***Departamento de Historia, Geografía y Comunicación. Facultad de Humanidades y Comunicación. Universidad de Burgos. Paseo de los Comendadores, s/n. 09001 BURGOS (España).E-mail: mmar@ubu.es ****Departamento de Geografía. Facultad de Geografía e Historia. Universidad de Salamanca. Calle Cervantes, s/n. 37002 SALAMANCA (España).E-mail: jip@usal.es

1 Este artículo se inscribe en el Proyecto de Investigación I+D CSO2016-79756-P (AEI/FEDER, UE). Ministerio de Economía, Industria y Competitividad, Programa Estatal de Fomento de la Investigación Científica y Técnica de Excelencia, Subprograma Estatal de Generación de Conocimiento, convocatoria 2016. 


\title{
Tourism and wine development in mountain areas with "high heritage density"
}

\begin{abstract}
The promotion of wine tourism is becoming an increasingly frequent strategy in the Douro wine regions. They have consolidated their productivity around quality wines and now highlight the heritage elements of landscapes linked to production. However, at the same time, in the least transformed areas with fragile environments but a high concentration of heritage assets -that position them as tourist destinations-, this wine sector is acting as a stimulus in the revival and competitive conservation of vineyards, more and more valued and recognised in the landscape as a tourism generator. To illustrate this process, this paper analyses the dynamics of vineyards cultivated in environments with a high density of heritage elements such as the Sierra de Salamanca (Spain).
\end{abstract}

Keywords: Tourism, heritage, wine, landscape, Sierra de Salamanca.

\section{INTRODUCCIÓN}

En las últimas cuatro décadas, el sector vitivinícola se ha convertido en una de las piezas más sólidas de la economía rural de Castilla y León. Los datos que recientemente proporcionaba la Plataforma de Competitividad Productiva Vitivinícola de la Junta de Castilla y León ${ }^{2}$ son elocuentes de su relevancia en el sector agrario (casi 75.000 hectáreas) e industrial (650 bodegas activas) y en la actividad económica en general (la producción media al año supera los 2,1 millones de hectolitros, lo que representa un volumen de negocio de 850 millones de euros); pero también de su impacto social (da empleo a 19.000 personas) y territorial (la mayor parte de estos empleos se generan en el medio rural). No obstante, estas cifras no deben ocultar la diversidad de situaciones que se dan en el complejo mundo del vino en una región diversa y tan contrastada. En las llanuras centrales del interior de la cuenca, los viñedos, que vivieron el azote de la despoblación de los años sesenta y setenta de la pasada centuria, se han reactivado al amparo de figuras de calidad tan renombradas como las Denominaciones de Origen Ribera del Duero, Rueda o Toro. Estas comarcas han visto como se modernizaba el viñedo, haciendo a los paisajes vitivinícolas evolucionar desde sus formas tradicionales (pequeños pagos, plantación en vaso, cepajes variados...) a otras nuevas donde dominan los marcos de plantación alineados, en conducciones de espaldera dotadas de sistemas de riego por goteo, y una trama parcelaria de fincas de mayor tamaño. A ello ha contribuido igualmente la edificación, año tras año, de nuevas bodegas, algunas de diseño vanguardista, icónicas en ciertos casos al estar firmadas por arquitectos de reputación mundial. Como consecuencia de esta apuesta, de un saber hacer de siglos y de las características particulares del medio, los vinos de estas comarcas se han situado entre los más cotizados y reconocidos por su calidad. Consolidada esta faceta productiva, y como respuesta a la fuerte competencia internacional y al des-

2 http://agriculturaganaderia.jcyl.es/web/jcyl/AgriculturaGanaderia/es/Plantilla100Deta1le/1246464862173/_/1284734377605/Comunicacion 
censo del consumo de vino en el mercado interior, instituciones y agentes involucrados en el desarrollo local y en el negocio vitícola, están afianzando su estrategia hacia la puesta en valor de los activos intangibles que se vinculan a estos paisajes vitivinícolas, integrando en ellos los restos de una tradición secular (barrios de bodegas, lagares, monasterios, castillos...) convenientemente reconvertidos. La marca del paisaje y del territorio, labrada en el marco de los vinos de calidad, y la experiencia y vivencia del vino en su integridad (bodega-viñedo) se pone así al servicio de consumidores y visitantes con el desarrollo de una dinámica actividad enoturística.

La Ribera del Duero es un ejemplo expresivo en este sentido. En su oferta turística diseñada con alcance internacional- se encuentran "una docena de hoteles de lujo, dotados con spa y bastantes con vinoterapia, que agrupan 546 habitaciones dobles, suites y lofts, para más de mil huéspedes, se completa en confort con la hospitalidad rural de posadas reales (4), posadas (10) y hoteles rurales (22) (...). La acogida restante, más común y para viajeros o turistas en general, la integran 123 casas rurales adecentadas y sin requisito de valor histórico, 69 establecimientos hoteleros de todo tipo (hoteles de 3 y 2 estrellas, hostales o pensiones) y 7 edificios de apartamentos, completando un conjunto sobresaliente en el medio rural de Castilla y León." (Molinero y Cascos, 2017: 2134). Por el lado de la demanda, y contabilizando solo las afluencias en su ruta del vino, ACEVIN (2017) confirma la consolidación de este espacio como el tercero más visitado-después de las Rutas del Vino y Brandy Marco de Jerez y del Penedés-. Recientemente el New York Times recomendaba la Ribera como uno de los 52 destinos turísticos del mundo que merecen una visita en 2018. Vitivinicultura y turismo generan así "un modelo de fertilización cruzada que ya ha sido puesto en evidencia en los clusters internacionales de enoturismo ${ }^{3 "}$.

Pero al tiempo que en las llanuras se desarrollaba este negocio altamente competitivo y fuertemente globalizado, los viñedos de los espacios serranos y de las profundas entalladuras fluviales que bordean la región no han gozado de reconocimiento hasta fechas recientes, cuando la despoblación y el abandono hacían mella casi irreparable en los elementos más conspicuos de unos paisajes agrarios de valor excepcional. En estas comarcas agrestes, las singulares condiciones del medio han limitado -aunque no excluido- el desarrollo de los patrones paisajísticos del productivismo. Sin embargo, y desde hace apenas dos décadas, y particularmente la última, estos espacios están apareciendo en la escena de los vinos de calidad apoyándose, precisamente, en los rasgos de autenticidad e integridad de unos paisajes que han quedado al margen de los cambios homogeneizadores de la modernización. Lo hacen impulsados por nuevos agentes que están poniendo en marcha iniciativas y estrategias novedosas, orientadas a hacer valer la calidad del vino, pero poniendo en valor los aspectos de mayor singularidad en el contexto global: variedades únicas y exclusivas, viñas viejas, prácticas sostenibles y la excelencia de sus paisajes. Es decir, las externalidades positivas y los activos intangibles que giran en torno al patrimonio y el paisaje, son un apoyo desde el que se impulsan unos vinos de calidad que emergen con fuerza desde la identidad local y la demanda turística generada por unos atributos culturales y naturales previamente institucionalizados.

3 Coloquio Internacional "Patrimonio, turismo y valorización de los territorios de la vid y el vino". Mendoza, Argentina, 22-24 de febrero de 2018. 
El presente artículo se plantea, como primer objetivo, ponderar el papel que el turismo está teniendo en la reactivación de estos espacios vitivinícolas frágiles y resilientes, partiendo de la hipótesis de que la afluencia de visitantes no solo juega un papel clave en las estrategias de mercado y en la patrimonialización de las áreas más consolidadas y bien posicionadas en el mercado del vino, sino que también actúa como palanca de transformación en aquellos espacios que ya gozan de un patrimonio natural y cultural reconocido institucionalmente, en torno al cual se ha consolidado una oferta turística relevante. Se pretende, también, como segundo objetivo, poner en evidencia las contradicciones que este nuevo marco plantea, de forma que no parece suficiente hacer mercadotecnia con el paisaje sin considerar el papel que la actividad agraria en general y la viticultura en particular, juegan en su calidad, y la consiguiente necesidad de una gestión que permita superar los problemas de abandono y deterioro acumulados.

Para ello, se ha elegido un estudio de caso, los viñedos de la Sierra de Salamanca. Por su fragilidad, densidad patrimonial y fuerte identidad local, estos viñedos ilustran una dinámica que cada vez resulta más evidente en otros entornos de la región que gozan de alguna figura de protección o reconocimiento, y que, por ello, se están conformando como destinos turísticos, abriendo nuevas posibilidades de promoción económica y social al aunar lo tradicional y lo moderno desde los principios de calidad y singularidad. Como planteamiento metodológico, se ha recurrido a la revisión bibliográfica más significativa y a la consulta de fuentes y documentos publicados en las distintas administraciones públicas y privadas, pero sobre todo al trabajo de campo, que incluye tanto el reconocimiento del paisaje y sus valores, como las entrevistas a bodegueros, viticultores, responsables de la DOP o restauradores. Todo ello ha servido para poner en evidencia que, frente al modelo productivista, "competitivo únicamente en precio del producto" se está avanzando hacia "modelos productivos más diversificados y diferenciados por su calidad y conexión con el territorio" (Plaza, Cañizares y Ruiz, 2017:566). En estos casos, el turismo actúa como un factor patrimonializador de primer orden (en el sentido de preservar, gestionar y poner en valor los recursos), pero ahora impulsando, bajo nuevos parámetros, prácticas y agentes, el sector vitivinícola serrano.

\section{LA FUERZA DEL TURISMO COMO FACTOR DE REGENERACIÓN DE LAS REGIONES VITIVINÍCOLAS "FRÁGILES"}

Gravari-Barbas explica cómo, forzados por la globalización y ante los nuevos desafíos competitivos a los que se enfrentan territorios y productores de vino, "el contacto directo entre el cliente y la empresa vitivinícola ya no se basa únicamente en el producto (vino, botella)", sino que "la calidad del intercambio entre el productor y el consumidor depende en gran medida de la capacidad de la bodega para ofrecer al cliente una experiencia completa que integre todos los elementos que componen el winescape (cava, la bodega y su arquitectura, el paisaje, las cualidades del lugar)", aspectos que, lejos de ser periféricos o secundarios, se están convirtiendo en "elementos centrales para el intercambio entre la empresa y sus clientes" (Gravari-Barbas, 2014: 240). Estas cuestiones colocan en una posición central el turismo del vino o enoturismo, que Damiá Serrano enmarca en las prácticas del turismo cultural, considerándolo "una tipología de turismo centrada en el patrimonio natural y cultural de las regiones vitivinícolas que centra su interés en las técnicas agrícolas 
del cultivo de la vid y de la elaboración y crianza de los vinos, y donde el turista adopta un papel activo en el proceso de consumo de la experiencia turística" (Serrano, 2011:21).

En esa experiencia integral, el paisaje asume un papel protagonista, pues vincular la calidad del producto (el vino) a la calidad del lugar (el paisaje) permite que el destino se "venda" más fácilmente, en particular si sus cualidades gozan de un reconocimiento institucional de rango internacional. Algunos autores (Briffaud y Brochot, 2010:19), hacen ver esta cuestión a propósito de los paisajes que figuran en la Lista de Patrimonio Mundial de la UNESCO, con el específico reconocimiento de vitivinícolas, cuando mencionan que la selección de estos lugares parece a menudo obedecer a razones económicas más que a la esencia o naturaleza excepcional del bien declarado. De hecho, como sugieren estos autores, los bienes que se suman a la Lista pasan a formar parte de los itinerarios turísticos como un atractivo incuestionable. En este sentido, coinciden con Fernández y Silva cuando señalan que "hace varios decenios que los agentes sociales, económicos y gubernamentales que operan en los territorios muestran un creciente interés por el reconocimiento institucional de los bienes patrimoniales en ellos existentes. Esto responde a su valoración cultural, pero también a una estrategia de marketing y visibilidad espacial, a menudo enmarcada en programas de desarrollo territorial para los que los bienes patrimoniales -como recursos específicos y no deslocalizables- son considerados activos competitivos básicos" (2015: 254).

En cualquier caso, la calidad del espacio de destino es fundamental en el enoturismo, toda vez que la experiencia del vino exige presencia, pues no se trata solo se degustar el producto sino de beber el paisaje. Esta apreciación es importante, pues en la construcción de esos destinos rurales de postal concurren valores naturales y culturales que deben articularse y combinarse, y el paisaje de postal es un argumento integrador que refuerza y consolida el valor patrimonial que posee el territorio. Por esta razón, el enoturismo en su formulación más amplia, funciona como "una formidable maquinaria productora de patrimonio" de tal forma que "...hoy en día son las fuerzas de la globalización las que intervienen en la producción de paisajes patrimoniales...” (Gravari-Barbas, 2014:241).

Constatada esta realidad, resulta de interés ponderar cómo el turismo del vino (en la compleja combinación de espacios, operadores y visitantes) puede actuar en otro sentido. Ocurre cuando los destinos turísticos se han asentado sobre otros valores y principios (naturales o culturales) y la afluencia de visitantes se convierte en una fuerza de activación de los vinos y viñedos. De nuevo, el turismo actúa como un factor de transformación decisivo que permite poner en valor los atributos menos transformados del paisaje vitivinícola. Activa una oferta que ve la oportunidad de aunar el vino de calidad a la singularidad de su paisaje como garantía de autenticidad y, al tiempo que desarrolla otros productos asociados (restauración, hospedaje, rutas, etc.), encuentra una salida a unos viñedos y a unos vinos abocados, si no a la desaparición, sí a la marginalidad. Es decir, el turismo actuaría como factor de regeneración de las regiones vitivinícolas "frágiles", particularmente en los ámbitos que tienen una notable superposición de figuras de reconocimiento espacial, como es el caso de uno de estos espacios de montaña de "alta densidad patrimonial", la Sierra de Salamanca, al sur de la provincia española homónima.

En la Sierra de Salamanca (la Sierra) el viñedo no se encuentra ocupando extensiones masivas, ni el número de bodegas es elevado, ni su proyección comercial está entre las más 
destacadas del país..., ni de la región siquiera. Tiene otra escala, la de lo modesto, pequeño y cercano: la escala local. Pero, al tiempo, es un interesante "laboratorio" para entender las formas que reviste este proceso de reactivación del viñedo impulsado por la fuerza del turismo y las contradicciones que le acompañan. Sobre todo, porque esa reactivación se está basando en planteamientos agronómicos y enológicos distintos, más orientados a unas prácticas sostenibles, acordes con los presupuestos de la figura de protección patrimonial de la Unesco en la que se inscriben: la Reserva de la Biosfera Sierras de Béjar y de Francia. Esta "marca" de reconocimiento, el inmediato producto del programa Hombre y Biosfera, además de poner en evidencia las nuevas formas de relación entre cultura y naturaleza, puede abrir interesantes cauces a la difícil tarea de gestionar una estrategia de desarrollo centrada tanto en la calidad de los caldos como en la singularidad de unos paisajes vitivinícolas escasamente transformados, pero necesariamente evolutivos y fuertemente afectados por el abandono.

\section{LA SIERRA DE SALAMANCA: DE LA CRISIS DEL SISTEMA AGRARIO TRADICIONAL A ESPACIO ARQUETIPO DEL TURISMO RURAL}

La Sierra de Salamanca es uno de esos espacios agrarios que quedaron al margen de las corrientes productivistas, donde la descomposición de una rica y compleja sociedad serrana, cuya economía se basaba en el vino, el aceite, la miel, el comercio, la artesanía... devino, merced a los nuevos valores sociales, en una suerte de sierra mítica, de territorio fabuloso, apológico, evocador (Llorente, 2001: 30-31), redefinido en clave patrimonial y consolidado como uno de los espacios de mayor "densidad patrimonial" (Silva y Fernández, 2017) y una de las comarcas más destacadas del turismo rural de Castilla y León.

\subsection{Crisis de los sistemas agrarios tradicionales y abandono del viñedo}

Llorente (1995) ha estudiado con precisión la crisis de la actividad agraria de esta comarca; la lenta descomposición de sus estructuras agrarias y el abandono de los espacios productivos. La trayectoria seguida por el cultivo del viñedo y la elaboración del vino es una expresión fiel de este proceso.

Las dificultades de todo entorno serrano son evidentes para la práctica de una agricultura productivista. Ha ocurrido en el resto de Europa, y los ejemplos de abandono del viñedo de montaña se encuentran por doquier (Minvielle, P., 2006). En este sector occidental de la Cordillera Central, pese a que las altitudes son relativamente modestas (Sierra de Tamames, 1.400 m; Sierra de Francia, 1.730 m) su condición montañosa se revela en los fuertes desniveles y agudas pendientes que resultan de la labor de disección llevada a cabo por el río Alagón y sus afluentes, que tienen en el Tajo un nivel de base mucho más bajo que el Duero, y en la zona de Quilamas y en la vertiente hacia Batuecas y Las Hurdes uno de sus más expresivos ejemplos. Esta labor erosiva sobre sustratos de desigual dureza (fundamentalmente granito y pizarra), es lo que confiere a este ámbito serrano su verdadera seña de identidad: el intenso abarrancamiento (García Fernández, 2012:352). No obstante, al configurarse como un gran murallón expuesto al suroeste, las condiciones de temperatura y humedad han favorecido el desarrollo de una agricultura singular, orientada a los cultivos leñosos (vid, olivar y frutales), cuyos frutos eran sustento de una actividad 
comercial muy intensa con las llanuras. De ahí el carácter esforzado y emprendedor de los serranos, que será clave en el resurgir del viñedo tras una fase de depresión profunda derivada de la falta de competitividad y crisis de los sistemas tradicionales y de la forma de vida de la sociedad que lo sustentaba. Su efecto más evidente ha sido el abandono de una parte sustancial de este terrazgo, con el consiguiente proceso de "asilvestramiento" y de ruina, pues "el tiempo y la desidia hacen mella en algunos bancales, ya que los paredones desmoronados no se levantan, en especial aquellos que soportan viñedos en zonas alejadas de los pueblos" (Llorente, 2001:37).

El abandono del cultivo se refleja en la retracción de una superficie que nunca ha sido fácil cuantificar, pues el viñedo no ha ocupado una superficie continua y en muchos casos aparece mezclado con el resto de cultivos leñosos. En todo caso, los Documentos 1T (producto de la operación estadística que permitía conocer los usos de suelo existentes en cada municipio) a mediados de los ochenta todavía elevaban a 2.045 las hectáreas cultivadas. Sin embargo, en 2014, los datos facilitados por la Asociación de Viticultores y Elaboradores de Vino de la Sierra de Salamanca (AVEVSS) apuntan que este número se habría reducido a poco más de 590 ha (2014:3). Del análisis geo-estadístico de los datos, realizado a través del SIGPAC, y considerando las superficies combinadas, esta cifra se podría elevar hasta las 752,97 ha. En todo caso, los datos son elocuentes para dar testimonio del intenso abandono producido en los viñedos situados en pagos más alejados o menos accesibles.

Pero el cese de la actividad también se ha hecho evidente en las bodegas. Muchas de las instalaciones pertenecientes a los antiguos bodegueros-almacenistas que comercializaban vinos a granel, particularmente para el norte de la península, fueron cerrando sus puertas en los años sesenta (Almacenes Nicolás González Hernández, en Miranda del Castañar, es un ejemplo entre otros muchos). De igual manera, las cooperativas, tan desarrolladas a finales de los años cincuenta hasta el punto de que cada pueblo contaba con la suya, y que fueron decisivas como estrategia de supervivencia de los pequeños viticultores para la comercialización del vino, poco a poco también han ido cerrando (Santibáñez de la Sierra, Villanueva del Conde, Garcibuey...). De hecho, en la actualidad, la única que pervive, la bodega cooperativa San Esteban, en el municipio de San Esteban de la Sierra, es un buen testimonio de aquel tiempo. Esta cooperativa se creó en 1959, y en 1994, con el apoyo de la iniciativa LEADER, vivió una notable renovación humana y material, abandonando los graneles tradicionales para orientarse a los vinos de calidad comercializados directamente (Llorente, 2001: 38). En la actualidad, con apenas un centenar de socios y 32 ha adscritas a la DOP, tiene dificultades de gestión y su tamaño se juzga a todas luces desmesurado (600.000 1), por lo que se recurre a alquilar sus instalaciones para la elaboración de vinos ajenos.

Como corolario de todo ello, los viticultores son cada vez más escasos y los derechos de plantación han sido vendidos a comarcas con un futuro más prometedor. Bien es cierto que el abandono no es absoluto, pues persiste la elaboración de vinos cosecheros para el consumo propio $\mathrm{y}$, hasta hace unas pocas campañas, se mantenía el cultivo de las viñas también para la venta de la uva a comerciales "gallegos" o de otras partes de la región. Como es común en las áreas de montaña, en la viticultura serrana tienen notable protagonismo agricultores jubilados o emigrantes que mantienen los viñedos con afanes diferentes. De ello deviene la falta de profesionalización (apenas hay agricultores propiamente dichos) y de relevo generacional, pero a estos viticultores se debe la conservación de unos viñedos que de otra 
forma hubieran sido abandonados. Son una parte activa en el mantenimiento de un paisaje que encierra unos valores culturales notables, pero que llamativamente están al margen de la consideración patrimonial que ha activado la función dominante en la Sierra: el turismo.

\subsection{El desarrollo y consolidación de un espacio de turismo de interior}

Tal y como apuntaba Llorente (2001), al tiempo que se descomponía su sistema económico tradicional, se ha ido armando otro basado en el turismo de interior, estructurado en torno a la puesta en valor de los recursos naturales amparados en figuras de protección como la Reserva Nacional de Caza de las Batuecas, las Zonas de Especial Protección para las Aves (ZEPAS), la ZEC (Zona de Especial Conservación) Las Batuecas-Sierra de Francia y el Parque Natural de las Batuecas-Sierra de Francia, declarado como tal por Ley 8/2000 de 11 de julio. De igual forma, los valores culturales tampoco se quedan a la zaga en interés, importancia y reconocimiento, y -dejando al margen bienes histórico-artísticos de índole material e inmaterial de carácter puntual- se manifiestan en aquellos núcleos que han mantenido los rasgos típicos de la arquitectura serrana, donde "la construcción tipo se corresponde con lo que se ha denominado «casa bloque en altura», o sea, "aquella que las dependencias se disponen en distintos pisos bajo el mismo techo y no en una sola planta" y donde "los muros exteriores presentan un tratamiento diferente según se trate de la parte baja, que es siempre de sillería o mampostería, o de los muros altos, que son de entramado de madera de castaño generalmente; este entramado va forjado en unos casos con adobes o con piedras menudas bien ajustadas, y rellenos de ripia los pequeños intersticios que entre éstas quedan. En muchas fachadas destaca un tipo de balcones que aquí llaman solana o corredor, que servía para orear las frutas, y que eran una parte imprescindible de la casa, incluso de las mal orientadas" (Llorente, 2001:40). Su densidad es sobresaliente: La Alberca fue el primer pueblo en España en ser declarado Conjunto Histórico en 1940, y en 2016 Villanueva del Conde hacía valer la disposición del terrazgo intramuros para obtener similar reconocimiento. Entre ambas fechas, Sequeros, Mogarraz, Montemayor del Río, Miranda del Castañar o San Martín del Castañar han sido declarados conjuntos históricos, mientras el Valle de las Batuecas se reconocía como sitio histórico. A ello se le agrega, desde 2006, la Reserva de la Biosfera de las Sierras de Béjar y de Francia.

Estos espacios han apostado por el turismo como forma de alentar la multifuncionalidad y dar salida a las difíciles condiciones del medio rural en los sectores de montaña, un rasgo muy común en el conjunto de la región castellanoleonesa, como se pone de manifiesto en la orientación preferente de los programas de Desarrollo Rural (Plaza Gutiérrez, J.I. 2002; Rico González, M.J., 2005; Alario y Baraja, 2006; Hortelano, L.A., 2016), hasta el punto de que el turismo rural se ha convertido en una de las piezas fundamentales de la economía regional, que en 2017 consolidó su liderazgo con 1.072.144 viajeros y más de 2 millones de pernoctaciones ${ }^{4}$ en alojamientos clasificados de turismo rural.

Resulta fácil comprender el elevado valor que para el desarrollo territorial tiene esta actividad económica al movilizar a unos viajeros motivados por "la experiencia" rural en todas sus formas (naturales y culturales) y productos (bienes, rutas, itinerarios...). Razón por

4 Boletín de Coyuntura Turística de Castilla y León. Resultados 2017. 
la que se aprecia, cada vez con más fuerza, el empeño por unir dos pilares fundamentales de la oferta de la Sierra: gastronomía y patrimonio. Si hoy el Plan Estratégico de Turismo de la Provincia de Salamanca 2016-2019, promovido por la Diputación, ve el conjunto de la provincia como destino multiproducto que ha sabido atraer un total de 1,3 millones de viajeros con 2,4 millones de pernoctaciones (2017), la Sierra ya apostó por el turismo desde los años ochenta, cuando la Asociación de Agricultura de Montaña (ASAM), convirtió esta comarca en una de las experiencias (junto a la Sierra de Urbión y a la Montaña Palentina) más exitosas de la región (Hortelano, 2016: 64). Un desarrollo que se manifiesta en el auge de los alojamientos que conforman su variada oferta. Considerando la evolución del número de establecimientos y de plazas ofrecidas en los municipios de la Sierra de Francia ${ }^{5}$, los alojamientos rurales han pasado de 76 en el año 2000 (repartidos en 62 casas de alquiler, 10 casas rurales de alojamiento compartido, 3 centros de turismo rural y 1 posada) a 153 en 2017 (repartidos en 116 casas rurales de alquiler, 17 casas rurales, 10 casas rurales de alojamiento compartido, 8 hoteles rurales y 2 posadas) (Vid. Figuras 1 y 2).

\section{Figura 1 \\ EVOLUCIÓN DEL NÚMERO TOTAL DE PLAZAS DE ALOJAMIENTOS TURÍSTICOS OFRECIDAS EN LOS MUNICIPIOS DE LA SIERRA DE SALAMANCA, 2000-2017}

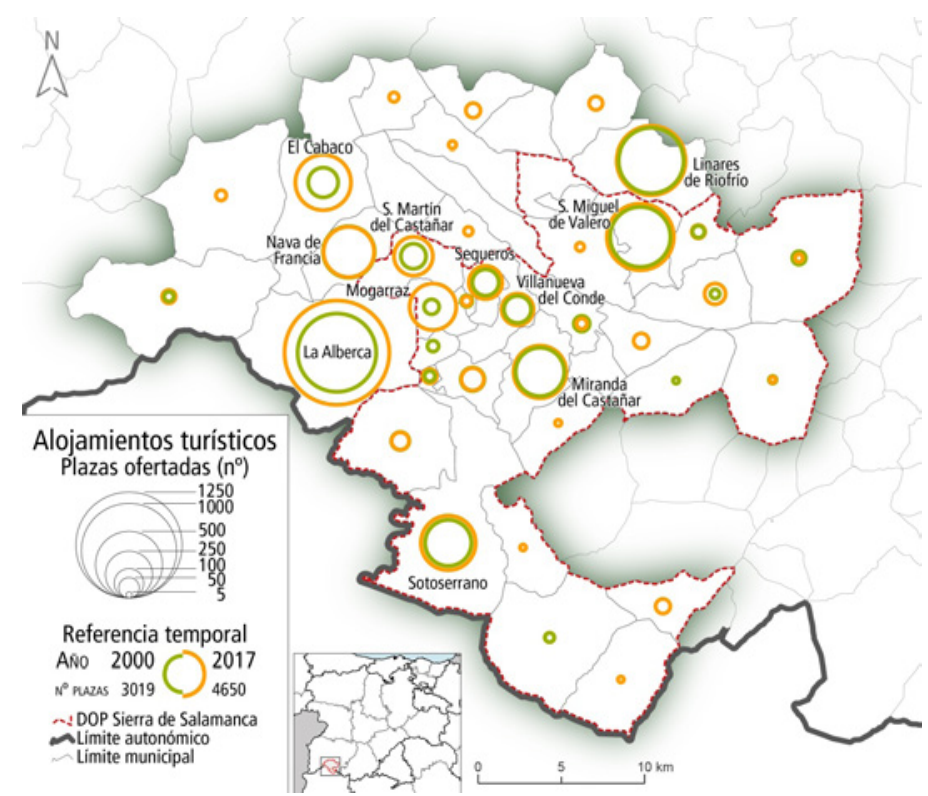

Fuente: Sistema de Información Estadística. Junta de Castilla y León. Consultado el 26/04/2018.

\footnotetext{
5 A efectos de representación cartográfica utilizamos la demarcación que plantea de J.M. Llorente (2001:28), ampliada hacia el Este para incluir la totalidad de municipios que forman parte de la DOP Sierra de Salamanca.
} 
Figura 2

NÚMERO DE PLAZAS OFRECIDAS EN LOS DISTINTOS TIPOS DE ESTABLECIMIENTOS EN LOS MUNICIPIOS DE LA SIERRA DE SALAMANCA, 2017

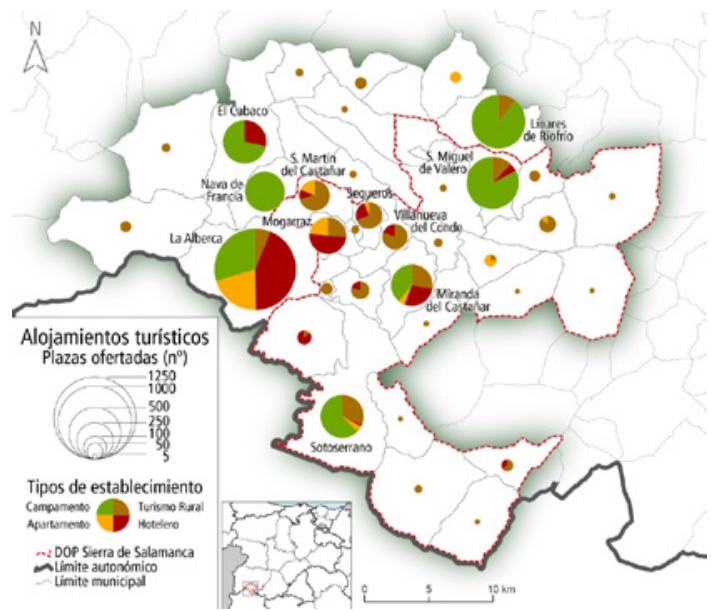

Fuente: Sistema de Información Estadística. Junta de Castilla y León. Consultado el 26/04/2018.

El número de plazas, por otro lado, ha pasado de 2.148 (448 en los distintos tipos de alojamientos de turismo rural, 530 en hoteles y 1.147 en campamentos turísticos) a las 3.334 (960 plazas de alojamientos de turismo rural, 901 en hoteles, 372 en apartamentos turísticos y 1.111 en campamentos), mientras que el número de restaurantes se ha incrementado de 19 a 26 en estos diecisiete años.

Es fácilmente deducible que este incremento de la oferta responde a un aumento paralelo del número de visitantes. Aunque los datos al respecto son notablemente imprecisos, las informaciones facilitadas por la Diputación de Salamanca para los centros de visitantes de las distintas Oficinas de Información Turística de la comarca muestran un incremento desde 2012, y elevan la cifra en 2017 a 20.000 visitantes en la Alberca, 4.000 en Mogarraz, 4.500 en San Martín del Castañar y del orden de los 6.000 Sequeros (Vid. Cuadro 1)

\section{Cuadro 1}

EVOLUCIÓN DEL NÚMERO DE VISITANTES REGISTRADOS EN LAS OFICINAS DE INFORMACIÓN TURÍSTICA DE LA SIERRA DE SALAMANCA, 2012-2017

\begin{tabular}{|l|l|l|l|l|l|l|}
\hline MUNICIPIO & 2012 & 2013 & 2014 & 2015 & 2016 & 2017 \\
\hline LA ALBERCA & 13.661 & 15.106 & 17.070 & 21.652 & 21.933 & 19.257 \\
\hline MOGARRAZ & 1.900 & 1.899 & 1.380 & 1.185 & 6.360 & 4.060 \\
\hline SAN MARTIN DEL CASTAÑAR & 4.235 & 5.451 & 4.739 & 5.035 & 4.949 & 4.517 \\
\hline
\end{tabular}




\begin{tabular}{|l|l|l|l|l|l|l|}
\hline MUNICIPIO & 2012 & 2013 & 2014 & 2015 & 2016 & 2017 \\
\hline SEQUEROS & 77 & n.d. & 5.178 & 7.079 & 6.127 & n.d. \\
\hline TOTALES & $\mathbf{1 9 . 8 7 3}$ & $\mathbf{2 2 . 4 5 6}$ & $\mathbf{2 8 . 3 6 7}$ & $\mathbf{3 4 . 9 5 1}$ & $\mathbf{3 9 . 3 6 9}$ & $\mathbf{2 7 . 8 3 4}$ \\
\hline
\end{tabular}

Nota: Los datos se refieren siempre hasta el 30 de septiembre del año citado. Fuente: Diputación de Salamanca.

A ello hay que agregar el turismo residencial, asociado a una consolidada presencia de la segunda residencia propiedad de personas directamente vinculadas con la emigración, o que, careciendo de este antecedente (muchas de ellas residentes habituales en la ciudad de Salamanca), han valorado las virtudes y potencial del entorno. Como aproximación a este fenómeno, baste constatar que, en 2015, y según datos de la Encuesta de Infraestructura y Equipamientos Locales, los municipios de la Sierra de Salamanca registraron una población máxima estacional de 19.229 habitantes. La comparación de este máximo estacional con el número de habitantes que figuran en el padrón ese mismo año (INE, 2015): 10.825 habs., permite deducir que el número de personas que acudieron a disfrutar de una segunda residencia a estos núcleos serranos ascendió a 8.404, lo que representó el 77,6 \% respecto a los empadronados, y en algunos casos (S. Miguel del Robledo, El Cabaco, El Maíllo, Pinedas, Rinconada de la Sierra, Valdefuentes de Sangusín y Valero) el número de habitantes no empadronados superó a los empadronados en el cómputo total de población estacional máxima. La segunda residencia, por lo tanto, está consolidada en el conjunto de la Sierra, pues en ningún municipio la proporción de población no empadronada sobre la empadronada es inferior al 50\%. La Alberca, el municipio turísticamente más emblemático y que contabiliza mayores cifras absolutas, tanto de número de habitantes empadronados (1.121) como de población máxima estacional (1.683), registra la menor proporción.

\section{Figura 3 \\ DISTRIBUCIÓN DE LA POBLACIÓN ESTACIONAL MÁXIMA RESPECTO A LA PERMANENTE EN LOS MUNICIPIOS DE LA SIERRA DE SALAMANCA, 2015}

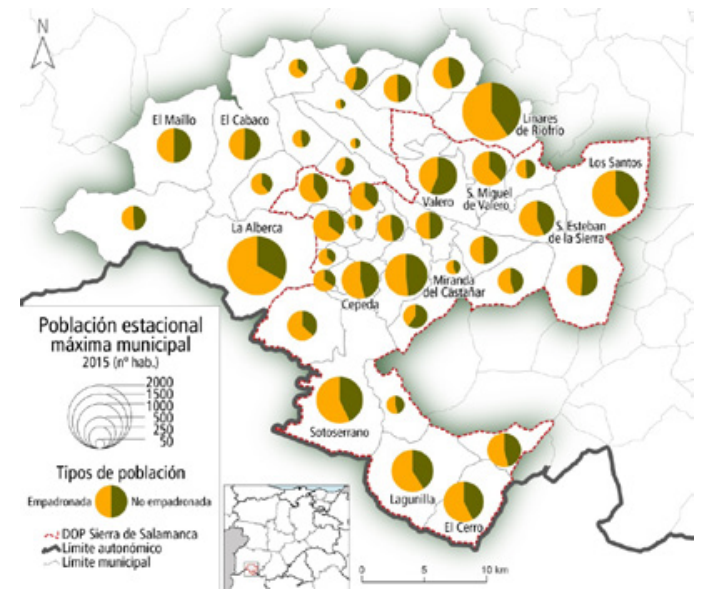

Fuente: Encuesta de Infraestructura y Equipamientos Locales (2015). 


\section{UNA NUEVA FASE PARA EL VINO: CALIDAD Y SINGULARIDAD}

En este contexto, y cuando la naturalización del terrazgo parecía irreversible, el viñedo y el vino se están reactivando al socaire de la calidad de sus caldos y de la singularidad de unos paisajes cada vez más valorados por los visitantes. Y lo hacen de la mano de nuevos agentes que operan desde el lado de la elaboración, bodegueros y enólogos, que incorporan nuevos planteamientos enológicos y perfilan estrategias para posicionarse competitivamente en el mercado del vino.

\subsection{Un nuevo planteamiento agronómico y enológico basado en la calidad}

Calidad y singularidad son conceptos centrales de la nueva andadura de los vinos serranos. La apuesta por la calidad como proyecto de futuro se inicia en la última década del s. XX cuando, en 1994 y al amparo de la figura de Vino de la Tierra, se "crean 4 modernas bodegas y se renueva la última cooperativa en funcionamiento con el fin de elaborar vinos de alta calidad y baja producción. Estas cinco bodegas, junto con viticultores de la zona, crean en 2007 la Asociación de Viticultores y Elaboradores de vino de la Sierra de Salamanca para proteger la comarca vitícola, promocionar los vinos y obtener la Denominación de Origen de la zona" (AVEVSS, 2017: 1-2). Esta fase se puede afirmar que culmina en junio de 2010, cuando, treinta años después de que fuera reconocida la primera DO de Castilla y León, Rueda, se publica la Orden AYG/806/2010 que reconoce la DOP Vino de Calidad de Salamanca, con una superficie de $482,1 \mathrm{~km}^{2}$ extendida por un total de 26 municipios.

Los datos que proporcionan los documentos elaborados por la DOP señalan que en esta nueva singladura se encuentran embarcados un total de 102 viticultores que aportan 105,33 ha, mientras son 6 las bodegas embotelladoras que comercializan los 820 hl calificados en 2015-16 . Poco a poco estas cifras van en aumento, pero los datos ponen en evidencia que la DOP está lejos de alcanzar las cifras que se manejan en otras comarcas vitivinícolas consolidadas. En realidad, son más los viticultores y elaboradores de vino que operan, si bien la naturaleza del espacio y sus peculiares condiciones físicas, hace que nos movamos siempre en el marco de la pequeña escala, lo que se traduce en estrategias diferentes, basadas en la singularidad.

\subsection{Nuevos agentes, nuevas estrategias y un factor común: la singularidad}

Esta apuesta por la calidad no resultaría en absoluto particular si no vinera de la mano de nuevos modelos de negocio basados en aspectos que se sintetizan en la que se sintetizan en la apuesta por producciones o cantidades de vino embotellado muy limitadas, la fuerte componente local (vínculo con el territorio, saber hacer, variedades locales, pagos concretos), las prácticas agronómicas sostenibles y la conexión con el turismo.

Alguno de estos rasgos -o todos- se pueden identificar en las bodegas que operan dentro y fuera de la DOP. Dejando al margen la bodega cooperativa de San Esteban que,

6 Datos de comercialización de las DOPs en la campaña vitivinícola 2015-2016. http://www.mapama.gob.es/ 
como indicamos, responde a un modelo precedente, en todas ellas la capacidad de elaboración es limitada, de tirada corta, al entenderse que es en este tipo de bodegas donde se encuentra el futuro de los vinos de calidad. De hecho, considerando las bodegas adscritas a la DOP, su capacidad oscila entre los 10.0001 de la bodega Don Celestino y los 81.000 1 de Bodegas y Viñedos Rochal, pero fuera de la DOP la tirada es menor y responden al modelo de microbodegas. Es el caso de Versos, Mandrágora Vinos de Pueblo (7.000 botellas de Tragaldabas y 1.000 de Molinillo en 2015), Viñedo Corneana (1.200 botellas). Otro tanto ocurre con las hectáreas de viñedos propios y adscritos, donde encontramos situaciones que van desde las 2 ha de Vinos La Zorra a las 7 ha de Viñas del Cámbrico, ampliándose en el mejor de los casos, hasta las 27 ha de viñedos propios de Perahigos o las 32 ha que abastecen a la Cooperativa de San Esteban.

Otro factor de singularidad es el fuerte vínculo territorial, que se pone de manifiesto en algunas bodegas que hacen ver su compromiso con la tradición en las formas de cultivo y elaboración (Bodegas y Viñedos Rochal), o la secuencia generacional en la "creación" de vinos (Bodegas Cuarta Generación), e incluso en el etiquetaje de las botellas, con la selección de nombres que indican los pagos de las viñas (Sierrahonda, Valdeherreros...). Pero es la apuesta por las variedades de uva local lo que constituye la verdadera seña de identidad de la comarca y uno de sus valores más singulares. En efecto, de la Sierra se dice que "es un paraíso de diversidad" por el "gran número de variedades diferentes, muchas de ellas autóctonas" (AVEVSS, 2017:8), destacando entre ellas la uva rufete "altamente adaptada a la zona" y que cubre aproximadamente el $60 \%$ de la superficie de viñedo, siguiéndole en importancia la garnacha (10\%) y el tempranillo (30\%) en tintos (calabrés y aragonés), así como el "viura" o el "verdejo serrano" en blancos. A diferencia del panorama dominante, donde son muy pocas las castas que se manejan, los "nuevos" vinos de la Sierra están apostando por las variedades fuertemente vinculadas con el territorio. A ello se le agrega el hecho de ser viñas viejas, "cultivadas desde tiempo inmemorial" (en expresión de la bodega Cámbrico) pues otra de las características más reseñables de este sector es la antigüedad de las cepas, "de tal forma que el $80 \%$ de las cepas tiene más de 50 años y el 50\% más de 80” (AVEVSS, 2017:8). Algo no baladí si consideramos el papel que tiene y la fuerte proyección que se augura a la viña vieja en la elaboración de los vinos "vigneron". En este sentido, la apuesta por los vinos de "villa", de "pueblo" o de "municipio" es una de las estrategias de la DOP. Una cuestión que está muy vinculada a la diversidad de pagos (orientaciones, pendientes, suelos...) de las que todas las bodegas enfatizan su singularidad, mediante la relación de las parcelas de las que proceden las uvas, o incluso el nombre del vino (Corneana) o de la bodega (Cámbrico).

Se trata de un aspecto que no se puede desligar de esa vitivinicultura "sostenible", respetuosa con el saber hacer tradicional, como otro factor común en estos proyectos. Se presenta como un valor añadido a la calidad y singularidad de los vinos, elaborados con las uvas que proceden de unos viñedos recuperados, rescatados del abandono, y donde las prácticas "respetan las tradiciones (...) y participamos en ellas para que no se pierda la esencia de nuestra geografía"7 (se indica en la página web de Versos); un saber hacer acumulado del que se aprende "poco a poco y dejándonos aconsejar por aquellos que saben

7 http://www.versosmicrobodega.com/ 
más. Nuestro proyecto es aumentar el número de viñedos de variedad autóctona, rufete blanco y negro, dentro del modelo tradicional de producción respetuoso con la tierra"8. Algo que se comparte y complementa con la apuesta por prácticas ecológicas, que emplean tratamientos naturales en la viña con el convencimiento de que "ofrecer a nuestros clientes lo mejor que da la tierra de forma natural. La ausencia de productos químicos de síntesis en nuestro viñedo y consecuentemente en nuestros vinos hace que estos sean más puros"9. De hecho, es la única bodega donde "tanto el viñedo como la elaboración de los vinos están certificados por el Consejo de Agricultura Ecológica de Castilla y León”.

El vínculo con el turismo, por último, es otro de los rasgos más destacados. Su conexión es explícita en muchos casos, tanto dentro como fuera de la DOP. Es el caso del que posiblemente sea el mayor proyecto hasta el momento, Bodega el Perahigo, con 27 ha de viñedos en Sotoserrano y una bodega en construcción en Miranda del Castañar a la que se asocia un hotel rural de 4 estrellas en una antigua casona de $1898^{10}$. Las bodegas Viñas del Cámbrico o Compañía de Vinos La Zorra (con 40.000 botellas de capacidad cada una), apuestan igualmente por el enoturismo, vinculando los vinos de calidad al edificio singular, la restauración, el alojamiento, y toda una serie de prácticas que incluyen visitas guiadas por los viñedos y las bodegas. Algo de lo que también participa Valor Empresarial Rural Sostenible (Versos-Microbodega, en San Martín del Castañar), que aúna un vino de calidad, elaborado de manera biodinámica, con la promoción turística (museo del vino, viñedos en bancales visitables, catas al aire libre o restaurante...).

A todos estos rasgos subyace una referencia implícita o explícita a la calidad del paisaje, al que se le otorga rango patrimonial. La aspiración a embotellar el paisaje aparece recurrentemente en su proyección comercial, hasta el punto de que bodegas como Perahigos abunden en que "todo el proyecto se realiza para acompañar al paisaje y fusionarnos con él, con criterios sostenibles y ecológicos". Pero esta relación es recíproca, y algunos elementos patrimoniales que componen el paisaje se han puesto al servicio de proyecto turístico.

\subsection{El patrimonio vitivinícola: un nuevo producto al servicio del turismo}

La relación vino, viñedo, paisaje y patrimonio es estrecho. De hecho, es común referirse a la "creación" del vino, en el sentido de que este proceso comienza en la viña, con su singularidad varietal multiplicada en la diversidad de los pagos, y cultivada conforme a unas prácticas asociadas al medio (relieve, suelos, clima, exposición) que requiere de diferentes soluciones (terrazas, muretes protectores) y de un manejo adaptado a los desafíos locales. El resultado sería un vino único, fruto de la combinación de todas las singularidades anteriores, y cuya elaboración, maduración, conservación y crianza se expresa en el territorio en elementos edificados no menos interesantes, como los lagares y bodegas. Un espacio que integra tanta complejidad de elementos naturales, culturales y arquitectónico-monumentales, bien puede llegar a tener entidad patrimonial por sí mismo al encontrar en el paisaje vitivinícola su pleno significado.

8 http://www.elperahigo.es/hotel-rural-bodega/

9 http://www.cambrico.com/

10 http://www.elperahigo.es/hotel-rural-bodega/ 
Los avances en el reconocimiento de los paisajes agrarios como una forma de patrimonio cultural tienen en la Carta de Baeza uno de los hitos más importantes en nuestro país (Castillo, 2013). Plaza, Cañizares y Ruiz hacían referencia a esta cuestión en esta misma revista, sistematizando, a partir del citado documento, los distintos elementos que configuraban el patrimonio vitivinícola, agrupándolos en un patrimonio material o tangible, los inmateriales o intangibles y el patrimonio natural y genético (Plaza, Cañizares y Ruiz, 2017: 554-555). La traslación de estas entradas al marco espacial que nos ocupa, ha llevado a subrayar unos atributos que, básicamente, se refieren al patrimonio genético asociado a un cepaje singular, donde domina, como se ha indicado, la variedad rufete; la antigüedad de las cepas; el poso que en el patrimonio inmaterial dejan las particulares condiciones en las que se ha desarrollado tradicionalmente el cultivo de la vid (Elías, 2016; Calvo, 1989); los bancales, manifestación de un terrazgo adaptado que permite el cultivo de la vid en vertientes con pendientes muy pronunciadas, además de favorecer el buen drenaje de las mismas; o los lagares tallados en la roca (lagares rupestres) que, junto a los bancales, constituyen otra de las piezas patrimoniales más significativas, y que tienen en el municipio de San Esteban de la Sierra su expresión más acabada.

Como se ha señalado, de todos estos elementos, que actúan como verdaderos vectores de patrimonialización, algunos se empiezan a integrar en la oferta del territorio como un producto turístico más. Y lo hacen formando parte de rutas e itinerarios, la versión que posiblemente más acerque a la consideración del territorio como bien cultural. En la Sierra de Salamanca se promociona la Ruta de los lagares rupestres de San Esteban de la Sierra, un itinerario circular que recorre diferentes pagos jalonados por este tipo de "construcciones" talladas en la roca, convenientemente señalizadas, y que aprovecha para realizar visiones paisajísticas, donde lo natural y cultural se aúnan. También se consideran como pretextos para marchas lúdicas o competiciones deportivas. Es uno de los pocos casos donde con mayor interés se ha intentado dar a conocer el patrimonio de la vid y el vino, a lo que recientemente se ha unido la iniciativa de la Diputación de Salamanca (a la que se han adherido otros ochenta socios públicos y privados) para desarrollar la Ruta del Vino de la Sierra de Francia. Este "producto", aprobado en 2016, se basa en la integración de los recursos y servicios turísticos de interés de una zona vitivinícola, planteados desde la autenticidad y la vocación vivencial. Un producto que se asienta sobre una estrategia de desarrollo socioeconómico integral del territorio, de cooperación público-privada y de valorización de la identidad y cultura vitivinícola del destino" (Hernández, 2017:43). No se trata solo en visitar bodegas y probar vinos, sino de poner en valor todos sus aspectos culturales, por lo que la idea de itinerario o ruta implica un recorrido por el proceso "creador" del vino, donde se aprecie el papel del cultivo en la configuración del paisaje como totalizador de fuerte impronta sensorial. De hecho, resulta significativo que en el Plan de Dinamización de la Ruta del Vino de la Sierra de Francia 2018 figure como actividad específica catar un territorio "una combinación de ceremonia/espectáculo/foro y degustación no solo de vino y productos de la zona, sino también de paisajes..."11. Los datos proporcionados por la gerencia de la ruta del vino para cinco bodegas revelan cifras modestas

11 Ruta del Vino de la Sierra de Francia. Plan de dinamización de la Ruta del Vino de la Sierra de Francia. Año 2018. https://rutadelvinosierradefrancia.com/2018/01/30/plan-de-dinamizacion-de-la-ruta-del-vino-sierrade-francia-2018/ 
de visitantes y recursos generados, pero auguran una participación aceptable si tenemos en cuenta la dimensión de la DOP y el hecho de que este es su primer año de andadura.

\section{Cuadro 2}

\section{VISITANTES A LAS SEIS BODEGAS INTEGRADAS EN LA RUTA DEL VINO SIERRA DE FRANCIA, 2017}

\begin{tabular}{|c|c|c|c|c|}
\hline \multicolumn{3}{|c|}{ VISITANTES } & \multicolumn{2}{c|}{ DATOS ECONÓMICOS } \\
\hline TOTAL & NACIONALES & INTERNACIONALES & $\begin{array}{c}\text { IMPORTE VISITA } \\
(1)\end{array}$ & $\begin{array}{c}\text { GASTO MEDIO POR } \\
\text { VISITANTE (2) }\end{array}$ \\
\hline 46 & 46 & 0 & 6 & 6,5 \\
\hline 22 & 22 & 0 & 5 & 3,4 \\
\hline 816 & 807 & 9 & 5 & 1,0 \\
\hline 166 & 165 & 2 & 10 & 6,6 \\
\hline 338 & 277 & 61 & 14 & 19,9 \\
\hline 1.388 & 1.317 & 72 & 8 & 7 \\
\hline
\end{tabular}

(1) Precio de la visita estándar del establecimiento $(€)$.

(2) Gasto medio de los visitantes en la tienda de la bodega o museo (€).

Fuente: Gerencia Ruta del Vino Sierra de Francia.

La Ruta de los Lagares Rupestres y la Ruta del Vino Sierra de Francia, son dos ejemplos claros drece la coordinación, bajo estrategias conjuntas, entre distintos actores. Sin embargo, se está lejos de integrar en este proceso a la totalidad de agentes y elementos. Así, apenas se ha actuado en las paredes o bancales, aunque se es sensible a sus valores culturales y puntualmente se restaura alguno en el marco del espacio natural. Se echa en falta avanzar en el reconocimiento de ese valor y actuar en la conservación o restauración de lo verdaderamente singular, lo que implica la necesidad de la gestión del paisaje en su conjunto. Y es en este aspecto donde se aprecia la mayor debilidad de este proyecto.

\section{LIMITACIONES, PROBLEMAS Y CONTRADICCIONES: LA FRAGILIDAD DEL VIÑEDO SERRANO}

Este esfuerzo y apuesta por una vitivinicultura diferente, asentada en la calidad y la singularidad, ha venido en buena medida de la mano de enólogos-bodegueros que, al amparo de la DOP, o fuera de ella, han actuado como agentes innovadores al apreciar el alto potencial de estos vinos y de sus valores materiales e inmateriales: valores exclusivos en entornos exclusivos. Pero el tirón de la producción de vinos se enfrenta a un problema: el abandono del viñedo. Este es un hándicap preocupante para el abastecimiento de uva de calidad y para la conservación del paisaje cultural de la Sierra. Por ello resulta contradictorio que se enfatice el valor del paisaje, pero no haya gestión del paisaje. A lo sumo una agregación de intervenciones que provienen tanto de los instrumentos sectoriales como 
de los organismos encargados de la protección de los espacios naturales y de los bienes culturales, pero que dejan huérfano el terrazgo donde se cultivan los viñedos.

En este sentido, la gestión del paisaje vitícola sigue siendo una asignatura pendiente en la Sierra; algo que no es exclusivo de la región, ni siquiera del país. A propósito de los paisajes culturales incluidos en la Lista de Patrimonio Mundial de la Unesco, Fernández y Silva señalaban que más que en un referente de buena gestión patrimonial, se ha "asimilado a la obtención de una marca de excelencia, y, en consecuencia, de un recurso muy competitivo" (2015:260).

\subsection{La lucha contra el abandono de la producción vitícola: el banco de viñedos como iniciativa innovadora que parte de la DOP}

Según el informe de la DOP de 2017, 114 viticultores vendimiaron $350.000 \mathrm{~kg}$ de uva en las 543 parcelas inscritas en la Denominación, lo que representa una superficie cercana a las 130 ha. Pero el viñedo supera con creces las 500 ha, por lo que la diferencia está en manos de viticultores que no tiene relación con la DOP. En una proporción elevada (el Censo Agrario de 2009 cifra en 397 las explotaciones que tienen viñedo en la comarca agraria de La Sierra), estos viticultores elaboran vinos para el propio consumo y venden el resto de la producción al mejor postor. Está muy arraigada la tradición de elaborar vino de casa, cosechero. Incluso estos vinos se promocionan año tras año en un concurso de cata de vinos artesanales, donde se premian los diferentes tipos de caldos jóvenes. El resto de la producción se vende a las bodegas o bien se comercializa fuera de la comarca. Antes, incluso se organizaban estas ventas colectivamente, en camiones que compraban "los gallegos". Ahora, como se desprende de las entrevistas realizadas, los viticultores son menos y la uva, particularmente la variedad rufete, es altamente demandada por las bodegas y escasea. Por ello, frenar el abandono, involucrar al segmento de viticultores en la promoción de los vinos y mantener la función agraria en un contexto con claros problemas estructurales exige prácticas imaginativas, aunque no necesariamente novedosas. En 2017 desde los órganos gestores de la DOP se anunciaba una de ellas: promover un banco de viñedo con el propósito de intermediar entre propietarios o viticultores y bodegueros.

Los bancos de viñedo tienen su origen en los bancos de tierras que en España se fueron desarrollando a partir de las primeras experiencias de Aragón a mediados de los años ochenta, (López Ramón, F.,2017) y que, con una orientación diferente, pasaron posteriormente a Asturias (Maceda, A. 1996) y Galicia (Porta, J. et al, 2012) con el objetivo de favorecer la intermediación entre propietarios y agricultores, ganaderos, forestales etc., a fin de evitar el abandono del campo, con la pérdida natural y patrimonial que ello conlleva. En el caso de Castilla y León, cabe subrayar la iniciativa del Consejo Comarcal del Bierzo de poner en marcha un Banco de Tierras en 2013 con el objetivo de intermediar para movilizar tierras abandonadas con vocación agrícola, ganadera o forestal, generando con ello actividad, conservación del medio, rejuvenecimiento etc. En este caso, se han puesto en marcha varias campañas de captación de viñedo, "que se han saldado con la recuperación de 1.114 fincas en desuso, lo que en superficie supone 100 ha”, si bien en notable 
precariedad, pues han sido cesiones de uso "donde el propietario sólo quiere que su viña esté productiva y a lo sumo vendimiar un par de cestos de uva para el autoconsumo"12.

La experiencia es prometedora y fácilmente exportable, pero no se puede disociar de las dificultades que conlleva el cultivo en espacios de montaña, por lo que, si además de la viña se quiere mantener el parcelario y las formas de cultivo (claves en el paisaje), se requiere la intervención de las instituciones directamente implicadas en la gestión de los espacios naturales o, en su caso, culturales para compensar la singularidad de las prácticas.

\subsection{Hacia una viticultura sostenible en un entorno patrimonial: las insuficiencias de la gestión en los Espacios Naturales y en los Conjuntos Históricos}

Producir en los entornos serranos es particularmente difícil. En su Informe de Situación DOP Sierra de Salamanca, la Asociación de Viticultores señala que existen más de 6.200 parcelas donde se cultiva viñedo, de lo que resulta un tamaño medio de 0,0950 ha/ parcela ${ }^{13}$. El acceso y la mecanización en este mosaico construido a base de retener la tierra mediante muros de piedra (terrazas o bancales) hacen particularmente duras las condiciones del laboreo. De ahí que el envejecimiento de los viticultores y la falta de relevo generacional comporte abandono, invasión de la maleza y de los animales silvestres. Con ello, no solo se arruinan los elementos que conforman este singular paisaje (con la consiguiente pérdida patrimonial), sino que los problemas ambientales -como los incendios y los procesos erosivos derivados de las fuertes pendientes- degradan los valores ambientales y productivos preservados durante generaciones.

De hecho, en el dossier técnico que avalaba la DOP se hacía relación expresa a esta circunstancia al indicar que "el terrazgo abancalado como forma de adaptación a la potencia de las pendientes de la Sierra [...] impide la erosión y facilita el mantenimiento de la estructura y de la riqueza orgánica del suelo", pero "imposibilita la mecanización del cultivo, obligando a recolectar a mano y trabajar el viñedo de forma sostenible y respetuosa con el medio ambiente" (AVEVSS, 2011: 5) ${ }^{14}$. Esta última apreciación es importante, pues está orientando claramente el sentido de la viticultura en la comarca, proclive a las prácticas cercanas a la agricultura ecológica en sus diferentes modalidades y grados, lo que es coherente con la apuesta de los bodegueros.

Ante esta confluencia de intereses, el mantenimiento de la viticultura y su paisaje asociado debería ser relativamente sencillo. Se trata de revertir en la explotación, en forma de compensación económica, tanto el valor del producto como de las externalidades positivas (ambientales, paisajísticas, patrimoniales...) que genera la actividad. Para ello, el primer paso sería considerar un precio razonable para la materia prima, de tal forma que, si se quiere evitar la utilización de productos químicos para eliminar las malas hierbas de los bancales y favorecer prácticas más respetuosas con el medio y la calidad de los vinos, el precio de la uva debe compensar esas particulares condiciones de producción, y esto compete a los agentes privados. Pero la consideración de externalidades positivas debe trascender este ámbito, toda vez que el problema del abandono no es solo productivo, sino

12 http://www.bancodetierrasdelbierzo.es/noticias.jsp

13 Informe de Situación. DOP Sierra de Salamanca. Superficie de viñedo 2014

14 http://www.dosierradesalamanca.es/wp-content/uploads/2012/01/dossier_sierra_salamanca.pdf 
ambiental y cultural, lo que justificaría la implicación de organismos e instituciones que tengan entre sus fines velar por el patrimonio natural y cultural.

Sin embargo, las figuras de protección natural y cultural están revelándose insuficientes en esta línea. En el caso de las primeras, buena parte del espacio productivo está fuera del Parque Natural de Las Baturecas-Sierra de Francia, pues no resultaba sencilla la gestión de los espacios donde domina la propiedad privada. Es significativo que el PORN de este espacio natural apenas haga referencia a la singularidad de su terrazgo y paisaje agrario, y que tan solo, y como precepto general, cifre entre sus objetivos "la utilización ordenada de los recursos y el mantenimiento de las actividades agrosilvoganaderas tradicionales que han permitido la conservación de los recursos naturales", así como la promoción de "las producciones agrícolas a las que se pueda adscribir una denominación de origen, etiquetas de calidad u otras calificaciones que las identifiquen con el Espacio Natural". Las segundas, centradas esencialmente en los núcleos declarados Conjuntos Históricos en diferentes momentos (La Alberca, Montemayor del Río, Mogarraz, Miranda del Castañar, San Martín del Castañar, Sequeros y Villanueva del Conde) solo muy recientemente se han dotado de herramientas de protección y gestión, como los Planes Especiales de Protección del Conjunto Histórico (PEPCH). Sin embargo, en los PEPCH apenas se habla de paisaje si no es para referirse a la incidencia de ciertas actividades económicas y, particularmente, de los valores naturales.

La insuficiencia de los mecanismos previstos en los Espacios Naturales y Conjuntos Históricos a la hora de proteger, ordenar o gestionar el paisaje agrario tiene mucho que ver con el hecho de que, tradicionalmente, las prácticas agrarias eran vistas como una agresión directa a los valores naturales y culturales, al tiempo que desde el sector agrario se interpretaba su vinculación a estos espacios como un freno para la actividad.

La necesidad de un impulso parece evidente, y concierne plenamente a la gestión del paisaje entendido como recurso en un contexto vivo y adaptativo. Es algo que se ha considerado como un valor en las declaraciones de los viñedos de la Lista de la UNESCO, pero no hace falta esperar a que esto suceda en un espacio que cuenta desde 2006 con el reconocimiento del citado organismo bajo la figura Reserva de la Biosfera.

\section{TURISMO SOSTENIBLE Y GESTIÓN INTEGRAL DEL PAISAJE EN EL MARCO DE LA RESERVA DE LA BIOSFERA}

Las Reservas de la Biosfera (RB) asumen el reto de intentar conciliar la conservación del patrimonio natural y cultural con el desarrollo sostenible, integrando y buscando las sinergias con otras figuras de protección. Y todo ello con el valor añadido que le otorga su condición de territorio demostrativo o piloto que se desprende de los objetivos generales progresivamente aquilatados y recientemente puestos al día en la Estrategia del MAB (2015-2025) y el Plan de Acción de Lima (2016-25) con su correspondiente Declaración relativa al Programa MaB y su Red Mundial Reservas de la Biosfera. Esta cuestión introduce un factor de responsabilidad que no siempre se ha entendido, pues en ocasiones solo se enfatiza el valor añadido que el reconocimiento otorga a sus productos y servicios visibilizados, desde 2016, bajo la marca "Reservas de la Biosfera". 


\subsection{Turismo sostenible en las Reservas de la Biosfera}

El desarrollo turístico en los espacios declarados como reserva de la biosfera se basa en su excepcional valor para mostrar "mediante experiencias singulares y diferenciadas"15 la relación de la sociedad con la naturaleza. En España, las RB aparecen como destinos turísticos muy vinculados a los Espacios Naturales, pero cuentan con estrategias propias, como el Club de Producto de Reservas de la Biosfera, que busca "generar una experiencia turística singular y diferenciada" a partir de las relaciones hombre-naturaleza; o la inclusión de cinco de ellas -entre las que se encuentra la Reserva de la Biosfera de las Sierras de Béjar y de Francia- en la Asociación de Ecoturismo de España, que asesora y da soporte a las empresas turísticas que trabajan con criterios de sostenibilidad ${ }^{16}$.

En la Estrategia de turismo sostenible en la Red Española de Reservas de la Biosfera se destaca la importancia que la afluencia de visitantes tiene en casi todas ellas, "por lo cual el desempeño social y económico de este sector puede superar el impacto de los sectores tradicionales, como la ganadería y la agricultura. Esto permite visualizar un escenario territorial, donde la población tiene diversas opciones de actividades económicas complementarias y necesarias ente sî' (Ángeles, D., 2017: 27). Después de hacer un diagnóstico sobre la situación de estos espacios, la autora citada realiza una serie de recomendaciones, entre las que destaca la necesidad de fortalecer la comunicación a la sociedad con ideas fuerza que abunden en la integración de lo natural y cultual, el desarrollo sostenible y el paisaje. Este aspecto es esencial, toda vez que la calidad de la experiencia turística se vincula "a los servicios culturales que brindan los ecosistemas a través del paisaje y otros valores intangibles, que son el principal factor de atracción para los visitantes" (Ángeles, D.,2017:21). Consecuentemente, para el desarrollo de la actividad turística conforme a los principios que la inspiran, parece condición previa imprescindible la existencia de un compromiso con el paisaje y los valores territoriales que contextualizan y soportan el patrimonio natural y cultural reconocido.

\subsection{La Reserva de la Biosfera de las Sierras de Béjar y de Francia y su compromiso con el paisaje}

La RB de las Sierras de Béjar y de Francia, se puso en marcha en 2006. Abarca 199.140,28 ha, repartidas en 88 municipios, e incluye todos los bienes culturales declarados (42 BICs, 8 de los cuales son conjuntos históricos), así como los espacios naturales de la Sierra de Béjar y las Batuecas-Sierra de Francia. A diferencia de otras, el compromiso de la gestión de la RB Sierras de Béjar y Francia con el paisaje se convirtió en una de sus señas de identidad. De hecho, entre sus proyectos destacan los orientados a "crear un nuevo modelo de desarrollo rural basado en la participación de la población en la gestión y el mantenimiento de la biodiversidad y el paisaje" (Pierna, J. et al, 2014: 231). Se guardaba coherencia con lo señalado en el Informe de Identificación Paisajística de las Reservas de la Biosfera Españolas en el Marco del Convenio Europeo del Paisaje, donde se apunta

15 https://www.biosferalagomera.es/turismo-y-reservas-de-la-biosfera/

16 MAPAMA 2017 Estrategia de turismo sostenible en la Red Española de Reservas de la Biosfera. 
que "si las Reservas de la Biosfera españolas lo aplican como referencia y lo "interiorizan" y cuentan con las pautas en él establecidas a la hora de elaborar sus herramientas y estrategias de gestión, probablemente se convertirían en pioneras a nivel mundial en este sentido" (Sánchez, et al, 2011:9). Así, el objetivo 2.5 del Plan Estratégico de la Reserva de la Biosfera 2009-2013 (prorrogado hasta 2020), que constituye de hecho la base de "las líneas generales de actuación y estrategias fundamentales del Plan de Uso y Gestión" de la Reserva, se orienta explícitamente al estudio y conservación del paisaje, incorporando acciones tendentes al análisis de los elementos que lo definen, contemplando procesos participativos, de educación y difusión, y diseñando unas líneas de acción prioritarias y un plan de actuación.

En el caso específico del viñedo existe una implicación directa al reconocerse el papel de la viña y el vino en la configuración socioeconómica y paisajística. Resulta significativo que, en el Catálogo Abierto del patrimonio inmaterial de las Reservas de la Biosfera Españolas, elaborado por Fundación Fernando González Bernáldez y EUROPARC-España (2016), la ficha que se envía desde las Sierras de Béjar y Francia sea precisamente la de un bien vinícola: la uva rufete, "variedad autóctona y predominante en la zona".

En el ámbito concreto de la gestión, la máxima excelencia para el ensayo y demostración de métodos de conservación y desarrollo sostenible en escala regional, tal y como prevé el Marco Estatutario de 1995 de la Red Mundial de Reservas de la Biosfera, se otorga a la zona núcleo -que está vinculada a los espacios naturales protegidos- mientras los viñedos se encuentran, en su mayor parte, tanto en la zona de Amortiguación (330 ha), como en la zona de Transición (407 ha), "donde las autoridades públicas, las comunidades locales y las empresas" se comprometen a fomentar y practicar formas de explotación sostenible de los recursos. Y es en estos ámbitos donde operan los nuevos actores que están impulsando el vino de la Sierra de Francia. En coherencia con el sentido de la RB, están comprometidos con las prácticas sostenibles, si no enteramente, sí al menos en una parte sustancial. Así, se manifiestan las posibilidades que ofrece poner las prácticas agrarias al servicio del medio ambiente, pero también el compromiso que estos actores adquieren con los valores paisajísticos de su entorno, revelando un espíritu y unas motivaciones desconocidas en otros ámbitos.

En este contexto, sería razonable generar un marco de confianza entre productores y bodegueros que facilitase un tipo de prácticas respetuoso con los valores patrimoniales vinculados al paisaje vitivinícola. Existen herramientas para ello, y tampoco faltan experiencias auspiciadas desde otros espacios. Es el caso de la RB de Urdaibai, con acciones tendentes a la recuperación de emparrados con vid medievales que bordean algunos caminos en el término de Busturia; o el caso de "saborea Lanzarote", en la RB de la isla del mismo nombre, enfocada al desarrollo del turismo gastronómico y la promoción de La Geria como paisaje cultural con una actuación encaminada a crear un producto específico para este espacio vitivinícola ${ }^{17}$. Conviene detenerse en la experiencia de Menorca, también una RB en el contexto de fuerte concentración turística, que planteó la "necesidad de perseguir un objetivo de carácter transversal: encontrar un equilibrio entre la obtención de renta de los agricultores, el mantenimiento del capital sobre el que se sustenta

17 https://www.biosferalagomera.es/turismo-y-reservas-de-la-biosfera/ 
el resto de actividades económicas y la no descapitalización natural". De ahí surgieron los "Contracte Agrari de la reserva de la Biosfera (CARB)", promovidos por el Consell Insular de Menorca el 2005 argumentado que "Disponer de un espacio rural ordenado territorialmente como tal, supone una contribución cultural y paisajística de la cual no debe huirnos su vertiente favorable para la actividad turística. Este último elemento es fundamental, puesto que nos encontramos en el mayor factor de externalidades positivas de la agricultura en favor del resto de la economía......"

Esta idea se puede hacer extrapolable al resto de RB, y particularmente en la Sierra, ya que pone en evidencia el papel de esta figura a la hora de coordinar y crear sinergias positivas entre la iniciativa de los bodegueros, los viticultores y las diferentes instituciones y actores con responsabilidad en hacer viable la actividad y así compensar a los agricultores por su papel en el mantenimiento del paisaje, planteamiento que subyace en el desarrollo de una PAC más multifuncional que empezó a ponerse en marcha en la UE hace ya algunos años.

\subsection{Los contratos territoriales: oportunidades y limitaciones para la conservación del paisaje vitivinícola en la Sierra de Salamanca}

En efecto, los contratos territoriales pueden ser una posible salida para limitar o revertir el abandono al compensar a los agricultores-viticultores comprometidos con un tipo de prácticas sostenibles que, al tiempo que dan calidad a las uvas, fomentan la conservación de los elementos que singularizan el paisaje. Contemplados en la Ley 45/2007 para el desarrollo sostenible del medio rural, de 13 de diciembre, como "un instrumento de apoyo a las políticas de desarrollo rural sostenible", orienta a las autoridades competentes para conseguir, entre otros fines, "mantener sistemas agrarios tradicionales de alto valor natural o cultural que en la coyuntura actual tienden al abandono (...) Conservar y restaurar la calidad ambiental, el suelo, el agua, el patrimonio natural y la biodiversidad autóctona silvestre, la diversidad genética agraria de base territorial, el paisaje rural y el patrimonio cultural (...) o contribuir a la consecución de los objetivos de conservación de los espacios de la Red Natura 2000 u otros espacios o áreas protegidas ${ }^{18}$.

La amplia discrecionalidad con la que cuentan las comunidades autónomas en materia agraria y las distintas formas de entender las prioridades entre sensibilidades políticas no les dieron mucho recorrido, pero su filosofía se ha integrado en mayor o menor medida en las acciones de los programas de desarrollo rural. En Castilla y León, el Programa de Desarrollo Rural $2014-2020^{19}$, establece una serie de propuestas de actuación que van en esta dirección. En la número 10, relativa al Agroambiente y Clima, se contemplan como relevantes las operaciones de apoyo "al mantenimiento de superficies con presencia de cultivos permanentes, como son principalmente el olivo, el viñedo, el almendro, el castaño y la higuera", lo que "se justifica por el alto riesgo de abandono de los mismos dada su escasa rentabilidad, así como las dificultades que su mantenimiento conlleva, además de favorecer la existencia de paisajes singulares en determinadas zonas que son el resultado

18 RD 1336/2011

19 Programa de Desarrollo Rural de Castilla y León 2014-2020. http://www.jcyl.es/web/jcyl/AgriculturaGanaderia/es 
de la interacción de la agricultura con el territorio". De esta forma, y por primera vez, se contempla como elegible "una medida de claros efectos paisajísticos como es la de cultivos permanentes, asociándola por otro lado a la presencia de determinadas especies arbóreas o arbustivas en las que se realizan prácticas agrarias tradicionales"20.

Esta medida, articulada mediante un compromiso o contrato de gestión, está claramente adaptada a espacios como el que nos ocupa. La ayuda, cuya cuantía asciende a 100 euros/hectárea, está condicionada a que los beneficiarios dispongan de parcelas de, al menos, 0,10 hectáreas con cultivos permanentes que tengan una densidad de 100 pies por hectárea y que cumplan alguna de las siguientes condiciones: estar situadas en terrazas o abancalamientos; tener elementos singulares (setos vivos o muros de piedra) en, al menos, cien metros lineales por hectárea; que la pendiente sea igual o superior al 10\%; o que estén ubicadas en los Parques Naturales de Castilla y León.

Llamativamente, y pese a que se estimaba que podían beneficiarse de esta subvención en torno a 500 agricultores y 5.000 hectáreas ${ }^{21}$, la relación de beneficiarios ${ }^{22}$ solo asciende a 37 en la convocatoria 2015 y bajan a 28 en la convocatoria 2016, con ayudas que oscilan entre los 100 y los 1.700 euros. De entre ellos, solo hay una solicitud que corresponda a la comarca serrana, lo que en buena medida viene motivado por la escasa presencia de agricultores que reúnan las condiciones de las convocatorias y por el limitado interés que suscita la medida (trámites farragosos, controles...). Este pobre resultado contrasta, sin embargo, con el obtenido en Menorca, cuando en los primeros años de andadura los Contracte Agrari (CARB) pasaron de 53 en 2005 a 146 en 2009²3, evidenciando el largo camino que aún queda por transitar en la despoblada y envejecida comunidad de Castilla y León.

\section{CONCLUSIONES}

El estudio de la Sierra de Salamanca pone de relieve que el turismo está siendo un revulsivo en la recuperación y el relanzamiento de los vinos serranos, convirtiéndose, si no en un factor determinante, sí en un cauce vivificador. Se corrobora de esta manera la idea de que el turismo no solo es una de las alternativas de futuro para la diversificación de actividades en las comarcas vitivinícolas ya consolidadas, sino que puede ser un factor decisivo para la recuperación de viñedos que en su momento no encontraron la oportunidad de modernizarse.

Porque el enoturismo no depende exclusivamente de la calidad de los vinos, sino de la experiencia multisensorial que envuelve el trabajo de la viña y la elaboración de los caldos, y que el visitante percibe en su integridad. En este contexto, el paisaje, por su condición de totalizador, juega un papel decisivo. Por ello, esta vía de recuperación del viñedo y del vino en los entornos frágiles no ha de centrarse exclusivamente en la labor

20 Ídem, p. 450.

21 https://agriculturaganaderia.jcyl.es/web/jcyl/AgriculturaGanaderia/es/Plantilla100Deta1le/1246464862173/_/1284714544543/Comunicacion

22 https://www.iberley.es/getpdf/subvenciones

23 http://www.agroecologia.net/recursos/jornadas/jornadas-allorca09/presentaciones/Contratos\%20territoriales.pdf 
de bodegueros y enólogos, que sin duda es importante y están situando en los catálogos vinos que apenas se conocían hacía una década. El paisaje es algo más que forma y significado, mejor o peor presentadas en las estrategias de promoción y posicionamiento en el mercado: es ante todo función. De ahí la necesidad de mantener una agricultura viva; de una gestión participativa e integradora; de un proyecto común, en suma, que aúne intereses de bodegueros, viticultores y agentes de promoción turística.

En este sentido, la declaración de Reserva de la Biosfera en las Sierras de Béjar y de Francia abre una vía de gran interés y potencial. En primer lugar, porque el paisaje agrario en general, y vitivinícola en particular, es clave para la comprensión integral de un espacio serrano, hasta ahora fragmentado entre los conjuntos históricos y los espacios naturales. En segundo lugar, porque aunque no dispongan de medios adecuados, las RB sí gozan de legitimidad para incentivar y activar políticas tendentes a la ordenación y protección de los elementos de mayor valor patrimonial vinculados al vino (en los patrones específicos de aprovechamiento, estructuras y edificaciones asociadas a la producción y manejo vitícolas y vinícolas), pudiendo confeccionar un proyecto de gestión sólido y realista, con estrategias multifocales que concilien el mantenimiento de los rasgos tradicionales con las necesidades de un espacio vivo y económicamente activo.

\section{BIBLIOGRAFÍA}

ACEVIN (2017): Informe de visitantes a bodegas y museos del vino asociados a las Rutas del Vino en España. ACEVIN-Rutas del Vino en España. Disponible en https://www. wineroutesofspain.com/bd/archivos/archivo873.pdf

ALARIO, M. y BARAJA, E. (2006): «Políticas públicas y desarrollo rural en Castilla y León ¿Sostenibilidad consciente o falta de opciones? LEADER II», Boletín de la Asociación de Geógrafos Españoles, no 41, pp. 267-294.

ÁNGELES, D. (2017): Estrategia de turismo sostenible en la Red Española de Reservas de la Biosfera. MAPAMA, UNESCO. Disponible: http://rerb.oapn.es/images/ PDF_publicaciones/Documento_final_estrategia_turismo_RB.pdf.

AVEVSS (2014): Informe de Situación. DOP Sierra de Salamanca. Superficie de viñedo 2014. Documento Inédito.

AVEVSS (2017): Sierra de Salamanca. Denominación de Origen Protegida. Dossier Técnico. Disponible en http://www.dosierradesalamanca.es/wp-content/uploads/2017/02/ dossier_DOP_SSa.pdf

BRIFFAUD, S. y BROCHOT, A. (Eds.) (2010): Paysages d'exception, paysages au quotidien. Une analyse comparative de sites viticoles européens du Patrimoine mondial. Bordeaux, Rapport de recherche remis au ministère de l'Écologie, de l'Énergie, du Développement durable et de la Mer. Disponible en http://paysage-developpementdurable.fr/IMG/pdf/rf_briffaud1.pdf

CALVO, G. (1989): «Notas tradicionales sobre el cultivo de la Vid en la Sierra de Francia (Salamanca)», Revista Folklore, Tomo 9b. n 107, pp. 171-178.

CASTILlO, J. (Dir.) (2013): Carta de Baeza sobre el Patrimonio Agrario. Sevilla, Universidad Internacional de Andalucía, Disponible en http://www.patrimonioagrario.es/ pago/CARTA_DE_BAEZA_files/carta.pdf 
FERNÁNDEZ, V. y SILVA, R (2015): «Paisajes españoles susceptibles de ser incluidos en la Lista de Patrimonio Mundial de Unesco: Criterios para su identificación y selección», Boletín de la Asociación de Geógrafos Españoles, nº 68, pp. 253-278.

FUNDACIÓN FERNANDO GONZÁLEZ BERNÁLDEZ Y EUROPARC-España (2016): Catálogo abierto del patrimonio inmaterial de las Reservas de la Biosfera españolas. Organismo Autónomo de Parques Nacionales. Disponible en http://rerb.oapn.es/ visor-cartografico/106-centro-de-documentacion-y-difusion/publicaciones/publicaciones-de-la-rerb/355-catalogo-abierto-del-patrimonio-inmaterial-de-las-reservas-de-labiosfera-espanolas.

ELÍAS, L.V. (2016): Atlas del cultivo tradicional del viñedo y de sus paisajes singulares. Madrid, MECD y MAPAMA. Disponible en https://sede.educacion.gob.es

GARCÍA FERNÁNDEZ, J. (2012): Geografía y paisaje. Llanuras y montañas de Castilla y León. Valladolid, Universidad de Alicante y Universidad de Valladolid.

GRAVARI-BARBAS, M. (2014): «Winescapes. Tourisme et artialisation, entre lo global et le local», en Vinho, Patrimonio, Turismo e Desenvolvimento: Convergencias ao debate e ao desenvolvimiento das regioes vinícolas munidais. $N^{o}$ Spécial CULTUR, Revista de Cultura e Turismo, vol. 8, $\mathrm{n}^{\circ}$ 3, pp. 238-255.

HERNÁNDEZ, R. (2017): «Rutas del vino de España: enoturismo de calidad como motor de desarrollo sostenible», Ambienta, no 118, pp. 40-49.

INE: Padrón de Habitantes. Madrid, Instituto Nacional de Estadística. Disponible en http://www.ine.es

HORTELANO, L.A. (2016): Turismo rural en Castilla y León. Éxitos y fracasos. Tesis Doctoral. Acceso abierto en https://www.tdx.cat/handle/10366/128441

JUNTA DE CASTILLA Y LEÓN. Boletín de Coyuntura Turística de Castilla y León. Resultados 2017

LLORENTE, J.M. (1995): Tradición y crisis en los sistemas de explotación serranos: el ejemplo de las Sierras de Francia y Gata. Salamanca, Diputación de Salamanca.

LLORENTE, J.M. (2001): «La Sierra de Salamanca: pintoresquismo, transformaciones rurales y un futuro en clave turística», Medio Ambiente en Castilla y León, vol. 8, $\mathrm{n}^{\circ}$ 16 , pp. $27-43$.

LÓPEZ, F. (2017): «El efímero banco de tierras de Aragón», Revista Jurídica de Asturias, $\mathrm{n}^{\mathrm{o}} 40$, pp. 21-28.

LÓPEZ, F. (2017): «El efímero banco de tierras de Aragón», Revista Jurídica de Asturias, $\mathrm{n}^{\circ} 40$, pp. 21-28.

MACEDA, A. (1996): «El Banco de Tierras de Asturias, con especial referencia a su gestión de los programas de ceso anticipado de la actividad agraria», Ería, n 39-40, pp. 151-160.

MINISTERIO DE PRESIDENCIA Y ADMINISTRACIONES PÚBLICAS: Encuesta de Infraestructura y Equipamientos Locales. Periodos 2000, 2005, 2008- 2016. Disponible en https://ssweb.seap.minhap.es/descargas-eiel/

MINVIELLE, P. (2006): «La viticulture dans les Alpes du Sud entre nature et culture», Méditerrainée, $\mathrm{n}^{\circ} 107$, pp. 73-86.

MOLINERO, F. y CASCOS, C. (2017): «La revitalización del patrimonio territorial por la explotación vitícola en La Ribera del Duero: viticultura y paisaje», en Actas del 
XXV Congreso de la Asociación de Geógrafos Españoles. Madrid, 25-27 de octubre de 2017, pp. 2125-2137.

PIERNA, J. et al (2014): Sierras de Béjar y Francia, en Guía de Reservas de la Biosfera Españolas, Armonía hombre-naturaleza, MAPAMA-OA Parques Nacionales, pp. 227-232. Disponible en http://rerb.oapn.es/documentacion-y-difusion/publicacionesy-documentos

PLAZA, J.I. (2002): «El turismo rural en territorios periféricos: el ejemplo de algunas comarcas del oeste castellano-leonés», Investigaciones Geográficas, n 27, pp. 83-106.

PLAZA, J.J., CAÑIZARES, C. y RUIZ, A.R. (2017): «Patrimonio, viñedo y turismo: recursos específicos para la innovación y el desarrollo territorial de Castilla-La Mancha», Cuadernos de Turismo, no 40, pp. 547-571.

PORTA, J. et al (2012): «Sistema de Información del Banco de Tierras de Galicia», RISTI, $\mathrm{n}^{\circ}$ 9, pp. 27-41.

RICO, M. (2005): «El turismo como nueva fuente de ingresos para el merio rural de Castilla y León», Cuadernos de Turismo, $\mathrm{n}^{\circ}$ 16, pp. 175-195.

SÁNCHEZ, L. et al (2011): Identificación paisajística de las Reservas de la Biosfera españolas en el marco del Convenio Europeo del Paisaje. Disponible en www.gobiernodecanarias.org

SILVA, R. y FERNÁNDEZ, V. (2017): «El nuevo paradigma del patrimonio y su consideración con los paisajes: Conceptos, métodos y prospectivas», Documents d'Anàlisi Geogràfica, vol. 63/1, pp. 129-151.

UNESCO (2017): Una nueva hoja de ruta para el Programa sobre el Hombre y la Biosfera $(M A B)$ y su Red Mundial de Reservas de Biosfera, Estrategia del MAB (20172025), Plan de Acción de Lima (2016-2025) y Declaración de Lima. Disponible en http://unesdoc.unesco.org/images/0024/002475/247564S.pdf 